\title{
Pemanfaatan Limbah Pabrik Kelapa Sawit (PKS) Sebagai Energi Alternatif Biogas Melalui Sistem Biodigester
}

\section{Utilization of Palm Oil Waste (PKS) as Biogas Alternative Energy Through Biodigester Systems}

\author{
Ari Wibowo*, Ali Usman, Arief Hidayat, Rahmat Hari Purnomo \\ Universitas Sriwijaya \\ ${ }^{*}$ Penulis Korespondensi \\ Email: ariw87807@gmail.com
}

\begin{abstract}
Abstrak. Suatu agroindustri menghasilkan limbah yang tidak berguna dan mempunyai dampak terhadap lingkungan. Salah satunya adalah pabrik kelapa sawit dalam sehari menghasilkan lebih dari 1 ton limbah. Limbah pabrik dapat dimanfaatkan menjadi energi alternatif biogas melalui sistem biodigester. Metode yang digunakan dalam penbelitian ini adalah metode kuantitatif dan perolehan data berupa data primer, data sekunder dan metode eksperimen. Penelitian ini bertujuan untuk memanfaatkan limbah pabrik kelapa sawit menjadi biogas melalui sistem biodigester. Dari hasil penelitian diperoleh bahwa hasil gas paling banyak terdapat pada limbah pada kolam pertam yang dihasilkan dengan kecepatan sebesar 2,4 ml/jam untuk jumlah limbah $200 \mathrm{ml}$. Untuk 1 liter limbah yang diolah mampu menghasilkan $12 \mathrm{ml}$ gas setiap jam. Maka dalam 1 hari, limbah tipe 1 akan menghasilkan $288 \mathrm{ml}$ biogas setiap satu liter limbah.
\end{abstract}

Kata kunci: limbah, kelapa, sawit, biodigester, biogas

Abstract. An Agro-industry produces waste that is not useful and impacts the environment. One of them is a palm oil mill that produces over 1 ton of waste a day. It can utilize factory waste as alternative biogas energy through bio-digester systems. The method used in this research is quantitative methods and data acquisition in the form of primary data, secondary data and experimental methods. This research aims to use palm oil mill waste into biogas through the bio-digester system. From the results of the study it was found that the most gas results were found in the waste in the first pond produced with a speed of $2.4 \mathrm{ml} /$ hour for the amount of $200 \mathrm{ml}$ of waste. For 1 liter of treated waste can produce $12 \mathrm{ml}$ of gas every hour. So in 1 day, type 1 waste will produce $288 \mathrm{ml}$ of biogas per one liter of waste.

Keywords: waste, coconut, palm, bio-digester, biogas

\section{Pendahuluan}

Limbah adalah sisa dari suatu proses programsi yang berpotensi menjadi bahan pencemaran di suatu lingkungan (Karmana, 2007). Industri pabrik kelapa sawit merupakan salah satu penghasil limbah dimana dari 1 ton kelapa sawit menghasilkan limbah antara lain tandan kosong kelapa sawit (TKKS) 23\% (230 kg), limbah cangkang (Shell) 6,5\% (65 kg), wet decanter solid (lumpur sawit) $4 \%$ (40 kg), serabut (Fiber) 13\% (130 kg) serta limbah cair sebanyak 50\% (Mandiri, 2012). Limbah PKS sejauh ini belum terolah sempurna, limbah sawit 
hanya dibakar dan sebagian digunakan sebagai pupuk atau mulsa dengan cara dihamparkan pada lahan.

Berdasarkan penelitian tentang pemanfaatan limbah, TKKS memiliki potensi besar untuk dijadikan bahan bakar nabati (BBN). TKKS bisa diolah menjadi bioetanol dan bahan bakar pembangkit listrik tenaga biomasa (PLT Biomassa) karena menurut hasil uji laboratorium di Distrik Jair, Kabupaten Boven Digoel, Papua, TKKS memiliki jumlah kalor sebesar 4.492,7436 kalori/g (18.719,4656 joule/g), pati 11,550 \% bb dan selulosa 41,392 \% bb (Lab. Kimia ITB, 2010). Dari data Lab. Kimia ITB hanya limbah cair pabrik kelapa sawit yang tidak termanfaatkan. Oleh karena itu dalam mengatasi limbah tersebut diperlukan adanya pemanfaatan limbah sisa pembuangan yang berwawasan lingkungan dan berkelanjutan.

Biodigester adalah sistem pengolahan limbah dengan penambahan mikroorganisme sebagai strarter agar mempercepat proses dekomposisi material organik tanpa udara. Bodigester dapat menghasilkan biogas, pupuk cair organik serta suatu sistem yang memiliki tahapan penguraian masing-masing senyawa karbohidrat, lemak, dan protein dalam proses anaerobik.

Menurut Veziroglu (1991), biogas adalah campuran gas metana dan karbondioksida yang diproduksi secara anaerob setelah melewati tiga tahapan yaitu hidrolisis, asidogenesis, dan metanogenesis. Limbah dapur, kebun, kotoran hewan, pabrik dan lainnya dapat digunakan sebagai bahan baku pada pembuatan biogas.

Kalor pada biogas dengan kandungan metana $65-70 \%$ adalah $5200-5900 \mathrm{kkal} / \mathrm{m}^{3}$ dan energi panas sama dengan $1.25 \mathrm{kwj}$ listrik (Veziroglu, 1991). Sedangkan menurut Nurtjahya, (2003) gas metana murni (100\%) memmpunyai nilai kalor yaitu $8900 \mathrm{kkal} / \mathrm{m}^{3}$. Menurut Hammad (1996), kandungan metana pada biogas yang dapat membuatnya terbakar menurut minimal 57\% sedangkan menurut Hessami et al. (1996) adalah minimal 60\%. Keunggulan biogas sebagai energi alternatif adalah gas tidak berasap hitam, derajat panas lebih tinggi, lebih sedikit menghasilkan polutan, ramah lingkungan serta dapat disimpan.

\section{Bahan dan Metode}

Metode yang digunakan pada penelitian ini adalah metode eksperimen. Metode ekperimen merupakan cara penyajian pelajaran dengan melibatkan peneliti secara langsung untuk mengalami dan membuktikan sendiri sesuatu sehingga dapat mengetahui apakah suatu metode, prosedur, sistem, proses, alat, bahan, model dan lain-lain efektif dan efisien saat diterapkan pada suatu lingkungan (Bahri \& Aswan, 2006). 
Metode pengumpulan data yang digunakan ada dua, yaitu pengumpulan data primer dan sekunder. Data primer dikumpulkan dengan melakukan observasi langsung di lapangan. Dalam hal ini kami melakukan observasi langsung di daerah operasional salah satu perusahaan di daerah Ogan Ilir, Sumatera Selatan. Pengumpulan data sekunder yaitu melalui telaah pustaka dari buku ataupun sumber lain seperti jurnal dan artikel dari internet yang relevan dengan topik penulisan.

\section{Hasil dan Pembahasan}

Hasil observasi limbah pabrik kelapa sawit khususnya limbah cair bisa dijadikan sebagai energi alternatif biogas. Dengan metode biodigester limbah cair kelapa sawit dapat menghasilkan gas methana, dengan pengunaan bakteri acetophillic dan methanebacteria mempercepat proses dekomposisi material organik tanpa udara, tidak hanya menghasilkan gas tapi sistem biodigester juga menghasilkan pupuk cair.

Pembentukan gas methana dari limbah pabrik kelapa sawit tersebut dipengaruhi oleh suhu yang selalu stabil yaitu pada suhu $28^{\circ}-35^{\circ}$ yang menyebabkan bakteri acetophillic dan methanobacteria dapat membantu proses terbentuknya gas methana $\left(\mathrm{CH}_{4}\right)$ berkembang dan bekerja secara optimal.

Penelitian ini mengambil sampel dari masing-masing limbah mulai dari limbah yang baru keluar dari pengolahan kelapa sawit (tipe 2) dan limbah pada kolam pertama (tipe 1), serta limbah solid (tipe 3).

Pada Gambar 1 yang diamati adalah limbah yang berada pada kolam pengolahan pertama (tipe 1), limbah tipe ini memiliki kecepatan menghasilkan biogas sebesar 2,4 ml/jam dengan jumlah limbah $200 \mathrm{ml}$. Dari hasil ini, untuk 1 liter limbah yang diolah mampu menghasilkan $12 \mathrm{ml}$ biogas. Maka dalam 1 hari, limbah tipe 1 akan menghasilkan 0,288 liter biogas setiap liter limbah.

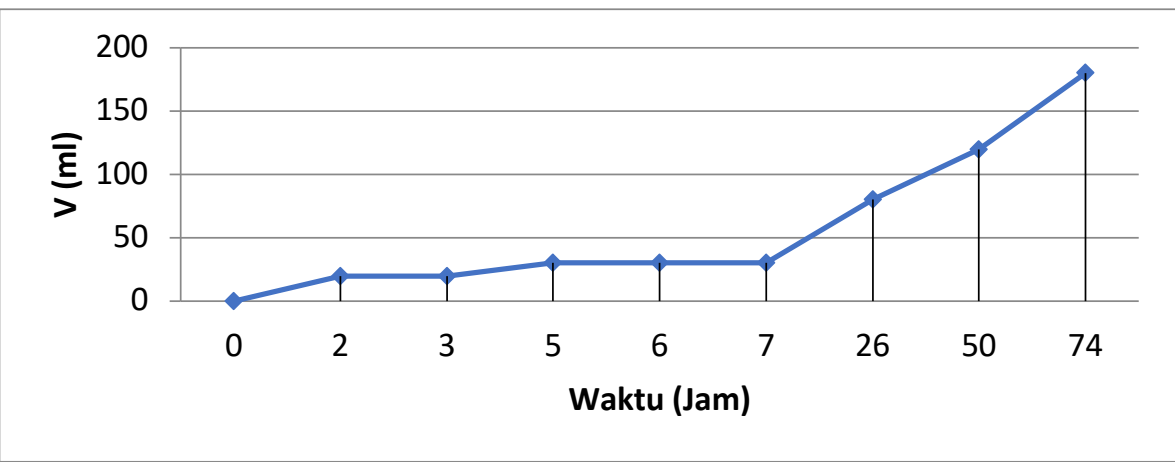

Gambar 1. Grafik gas yang dihasilkan limbah tipe 1 
Pada Gambar 2 yang diamati adalah limbah yang berada pada kolam pengolahan pertama yang dicampur dengan limbah 2 atau limbah yang baru keluar dari pengolahan tandan kelapa sawit, limbah tipe ini memiliki kecepatan menghasilkan biogas sebesar 1,8 ml/jam dengan jumlah limbah $200 \mathrm{ml}$. Dari hasil ini, untuk 1 liter limbah yang diolah mampu menghasilkan 9 $\mathrm{ml}$ biogas. Maka dalam 1 hari, limbah tipe 1 akan menghasilkan 0,216 liter biogas setiap liter limbah.

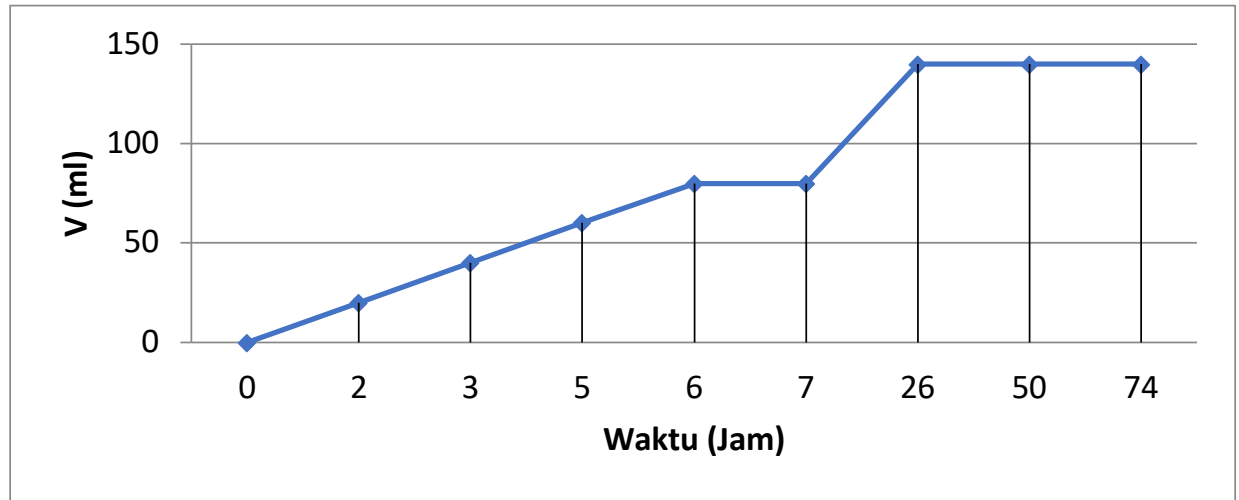

Gambar 2.Grafik gas yang dihasilkan limbah tipe 1 dan tipe 2.

Pada Gambar 3 yang diamati adalah limbah yang berada pada kolam pengolahan pertama yang dicampur dengan limbah solid atau lumpur sawit, limbah tipe ini memiliki kecepatan menghasilkan biogas sebesar 0,2 ml/jam dengan jumlah limbah $200 \mathrm{ml}$. Dari hasil ini, untuk 1 liter limbah yang diolah mampu menghasilkan $1 \mathrm{ml}$ biogas. Maka dalam 1 hari, limbah tipe 1 akan menghasilkan 0,24 liter biogas setiap liter limbah.

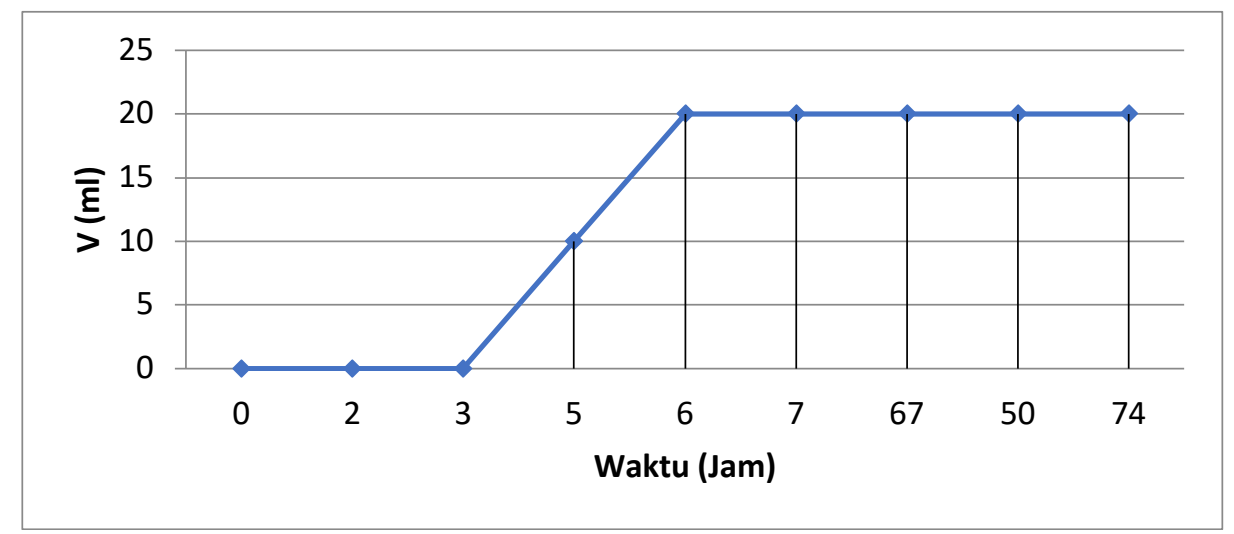

Gambar 3.Grafik gas yang dihasilkan limbah tipe 1 dan solid

Pada Gambar 4 yang diamati adalah limbah yang baru keluar dari pengolahan tandan kelapa sawit atau limbah 2 yang dicampur dengan limbah solid atau lumpur sawit, limbah tipe ini memiliki kecepatan menghasilkan biogas sebesar 1,3 ml/jam dengan jumlah limbah $200 \mathrm{ml}$. Dari hasil ini, untuk 1 liter limbah yang diolah mampu menghasilkan 6,5 $\mathrm{ml}$ biogas. Maka dalam 1 hari, limbah tipe 1 akan menghasilkan 0,156 liter biogas setiap liter limbah. 


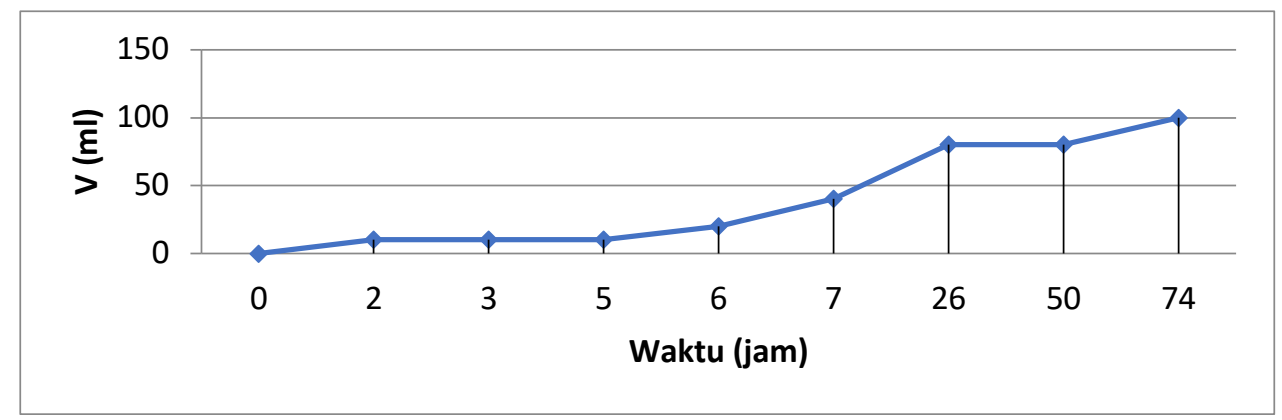

Gambar 4. Grafik gas yang dihasilkanlimbah tipe 2 dan solid

Dari empat gambar diatas, terlihat bahwa hasil gas paling banyak terdapat pada limbah pertama dengan kecepatan menghasilkan gas sebesar 2,4 ml/jam dengan jumlah limbah 200 ml. Dari hasil ini, untuk 1 liter limbah yang diolah mampu menghasilkan $12 \mathrm{ml}$ biogas. Maka dalam 1 hari, limbah tipe 1 akan menghasilkan 0,288 liter biogas setiap liter limbah.

\section{Kesimpulan}

Berdasarkan analisa dan pengolahan data dapat disimpulkan bahwa limbah Pabrik Kelapa Sawit (PKS) dapat dimanfaatkan untuk energi alternatif biogas melalui sistem biodigester dengan hasil biogas 0,288 liter/hari untuk setiap liter limbah pabrik kelapa sawit (PKS).

\section{Daftar Pustaka}

Bahri, S. \& Aswan, Z. (2006). Strategi belajar mengajar. Jakarta : PT. Rineka Cipta.

Hammad, S. M. (1996). Perfomance of A Full Scale Uasb Domestic Waste Water Treatment Plant. J. Instit. Public Health Eng. 1: 11-19.

Hessami M. A., Christensen S. \& Gani, R. (1996). Anaerobic Digestion of Household Organic Waste to Produce Biogas. Renewable Energy. 9 : 1-4, 954-957.

Karmana, O. (2007). Cerdas belajar biologi. Bandung : Grafindo Media Pratama.

PNPM Mandiri. (2012). Manual pelatihan teknologi energi terbarukan. Jakarta : DANIDA.

Nurtjahya, E. (2003). Pemanfaatan Limbah Ternak Rumensia Untuk Mengurangi Pencemaran Lingkungan. Di dalam : Makalah Pengantar Falsafah Sains. Bogor : Program Pasca Sarjana, Institut Pertanian Bogor.

Veziroglu, T. N. (1991). Hydrogen Technology For Every Needs Of Human Settlement. Int. Journal Hydrogen Energy. 12:99. 